\title{
The cytogenetic and molecular analysis of chronic myeloid leukemia in a tertiary care hospital of Sindh, Pakistan
}

\author{
Ikramdin Ujjan $^{1 *}$, Anwar Ali Akhund ${ }^{1}$, Abdul Mannan Baig ${ }^{2}$ and Ghulam Shah Nizamani ${ }^{2}$ \\ ${ }^{1}$ Department of Pathology, Liaquat University of Medical and Health Sciences, Pakistan \\ ${ }^{2}$ Department of Biological and Biomedical Sciences, Aga Khan University, Pakistan
}

\begin{abstract}
We performed a Cross sectional study to determine the frequency of Philadelphia chromosome and frequency of standard and variant translocation in chronic myeloid leukemia cases by the collaboration of Pathology department of Liaquat University of Medical and Health Sciences, Jamshoro and Isra University Hospital, Hyderabad from May to September 2014. A sample of 145 diagnosed cases of CML was selected according to inclusion. Bone marrow and peripheral Blood samples were collected in sodium heparinized bottles. Cytogenetic analysis was performed by karyotyping according to ISCN guidelines for human cytogenetic nomenclature using cytovision system for image analysis, reverse transcription polymerase chain reaction (RT-PCR) was performed to identify the various BCR-ABL transcripts. $\mathrm{Ph}+$ and $\mathrm{Ph}$-chromosomes were noted in 133 (91.7) and 12 (8.2\%) of cases respectively. Of $133 \mathrm{Ph}+$ chromosome, standard chromosome was noted in 121 (90.9\%), simple variant in 9 (6.7) and complex variants were noted in $3(2.2 \%)$ of cases. $\mathrm{Ph}+133$ (91.7\%) showed bcr-abl positivity in all subjects. Of 12 (8.2\%) Ph-subjects, 7 (\%) were bcr-abl positive and 5 (\%) were bcr-able negative. Sensitivity and specificity of bcr-abl transcripts was calculated at $95 \%$ and $100 \%$ respectively. The present study reports Philadelphia chromosome in $90.9 \%$ and variant cytogenetic abnormalities are low similar to reported from other countries. Proper assessment of the variant translocations requires better categorization of these translocations.
\end{abstract}

\section{Introduction}

Chronic myeloid leukemia (CML) is a myeloproliferative disorder characterized by the presence of the Philadelphia chromosome $(\mathrm{Ph})$ which is the derivative chromosome 22 of the translocation $t(9 ; 22)$ (q34.1; q11.2). Due to this rearrangement, the break-point cluster region $(B C R)$ gene at position $22 \mathrm{q} 11[1,2]$ is juxtaposed to the c-Abelson $(A B L 1)$ gene at $9 \mathrm{q} 34$, resulting in the $B C R-A B L 1$ fusion gene, encoding a constitutively active tyrosine kinase protein. The identification of this abnormality is important for the diagnosis of the disease as determined by the WHO Tumor Classificationland for treatment purposes. The first therapeutic choice, tyrosine kinase inhibitors, has shown great therapeutic efficacy [2]. The $\mathrm{Ph}$ is detected by G-band karyotyping in around $90 \%$ of CML patients among whom 5-10\% may have variant types [3-5]. Variant $\mathrm{Ph}$ chromosomes are characterized by the involvement of another chromosome in addition to chromosome 9 or 22 . It can be a simple type of variant when only one additional chromosome is involved, or complex, in which two or more chromosomes, besideschromosomes 9 and 22, take part in the translocation [6,7]. Variant Ph breakpoints occur in hotspots across the genome, usually in the G-light bands, within the cytosine and guanine (CG) richest parts of the genome [8]. However, the mechanism of variant $\mathrm{Ph}$ generation and the molecular bases of biological differences between classic $\mathrm{Ph}$ and variant $\mathrm{Ph}$ chromosomes are not fully understood [9]. Recently, Albano et al. [10] reported a study they performed on gene expression profiling (GEP) using microarrays to identify some of these differences [10].

The prognostic significance of variant $\mathrm{Ph}$ chromosomes has already been discussed [11] and it has been shown that the variant aberration does not impact on cytogenetic or molecular responses or even on clinical outcome. Variant $\mathrm{Ph}$ chromosomes are distinguished from additional chromosomal abnormalities or clonal evolution that drives disease progression. The clonal evolution is a reflection of a genetic instability that characterizes the transition to advanced phase [12]. In this situation, $\mathrm{i}(17 \mathrm{q})$, a second $\mathrm{Ph}$ and +8 are frequently found [1]. A search of local literature showed only a few studies had been conducted and reported, hence there is an urgent need to conduct more studies to explore cytogenetic and molecular abnormalities in chronic myeloid leukemia cases in our local population of Sind.

\section{Subjects and methods}

This cross sectional study was conducted at pathology department of Liaquat University of Medical and Health Sciences, Jamshoro and Isra University Hospital, Hyderabad from May to September 2014. A sample of 145 newly diagnosed cases of CML was included. Patients with acute leukemia, polycythemia, essential thrombocythemia and myelofibrosis, multiple myeloma were excluded from the study. Diagnosed cases of CML were included, while patients with acute leukemia, lymphoma, and multiple myeloma. Written informed consent was taken from the patients. The study was approved by the ethical committee of Isra University Hyderabad.

Bone marrow and Blood samples were collected in sodium heparinized vacutainer by applying appropriate techniques. $\mathrm{CBC}$ was performed on automatic hematoanalyzer, Sysmex XN 1000i. Cytogenetic analysis was performed by karyotyping according to

Correspondence to: IkramdinUjjan, Department of Pathology, Liaquat University of Medical and Health Sciences, Jamshoro, Sindh, Pakistan, Tel: 092 22 9213135; Fax: 09222 9210100, E-mail: Ikramujjan1973@yahoo.com

Key words: philadelphia chromosome, chronic myeloid leukemia, sindh

Received: May 08, 2015; Accepted: June 15, 2015; Published: June 17, 2015 
ISCN guidelines for human cytogenetic nomenclature using cytovision system for image analysis, reverse transcription polymerase chain reaction (RT-PCR) was performed to identify the various BCR- ABL transcripts by Qi guine kits.

The data was analyzed on SPSS version 21.0 (IBM, Corporation) and Microsoft excel. The continuous variables were presented as mean \pm SD and analyzed using student's t-test. Categorical variables were analyzed by Chi-square test and results were presented as frequencies and percentages. Data was presented in tables, graphs and charts. $\mathrm{P}$-value of $\leq 0.05$ was defined significant.

\section{Results}

Mean \pm SD of age was noted as $36 \pm 11.7$ years. Of 145 cases, most frequent age groups were 20-29.9 and 30-39.9 noted in $47.5 \%$ and $44.8 \%$ respectively. Of 145 cases, 109 (75.1\%) were male and $36(24.8)$ were female $(\mathrm{p}=0.001)$. Anemia was noted in $74.4 \%$ and hematocrit $(<20 \%)$ in $46.2 \%$ of cases. Leukocytosis of $>50,000 / \mu \mathrm{L}$ was noted in $68.5 \%$ of total cases.

$\mathrm{Ph}+$ and $\mathrm{Ph}$ - chromosome was noted in 133 (91.7) and 12 (8.2\%) of cases respectively (Figure 1). Of $133 \mathrm{Ph}+$ chromosome, standard chromosome was noted in 121 (90.9\%), simple variant in $9(6.7 \%)$ and complex variants were noted in $3(2.2 \%)$ of cases, shown in Table 1 and Figure 2. Simple and complex variant translocations are shown in table $1 . \mathrm{Ph}+133$ (91.7) showed bcr-abl positivity in all subjects. Of 12 (8.2\%) Ph- subjects, 7 (\%) were bcr-abl positive and 5 (\%) were $\mathrm{Bcr}-\mathrm{Abl}$ negative (Figure 3). Sensitivity and specificity of bcr-Abel transcripts were calculated at $95 \%$ and $100 \%$ respectively.

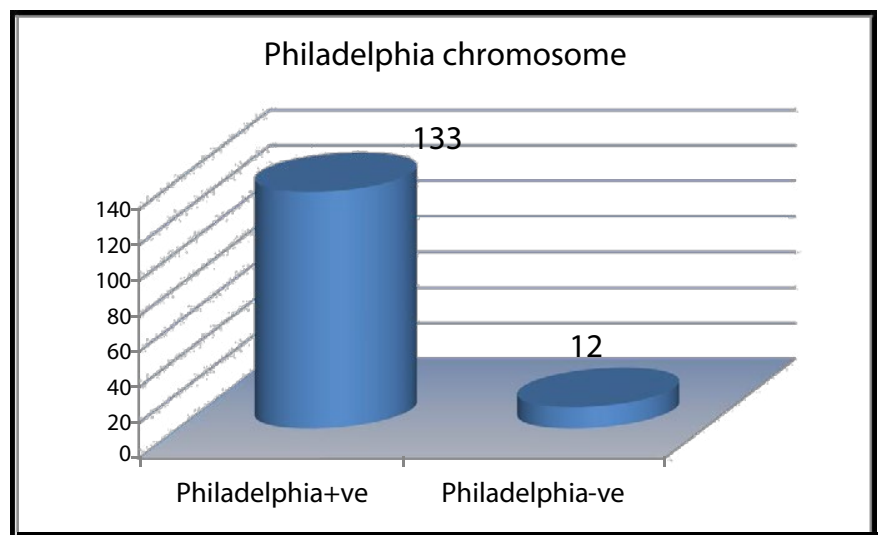

Figure 1. Frequency of Philadelphia chromosome.

Table 1. Simple and complex variants of Philadelphia chromosome $(n=12)$.

\begin{tabular}{|c|c|c|}
\hline & Variant Ph chromosome & Chromosome translocation \\
\hline 1. & Simple variant $\mathrm{Ph}$ & 46 xy $t(16 ; 22)$ \\
\hline 2. & Simple variant $\mathrm{Ph}$ & $46 x x t(19 ; 22)$ \\
\hline 3. & Simple variant $\mathrm{Ph}$ & $46 \times x \mathrm{t}(13 ; 22)$ \\
\hline 4. & Simple variant $\mathrm{Ph}$ & 46 xy $\mathrm{t}(17 ; 22)$ \\
\hline 5. & Simple variant $\mathrm{Ph}$ & $46 x x t(11 ; 22)$ \\
\hline 6. & Simple variant $\mathrm{Ph}$ & $46 \mathrm{xx} t(18 ; 22)$ \\
\hline 7. & Simple variant $\mathrm{Ph}$ & 46 xy $\mathrm{t}(15 ; 22)$ \\
\hline 8. & Simple variant $\mathrm{Ph}$ & $46 \times x \mathrm{t}(14 ; 22)$ \\
\hline 9. & Simple variant $\mathrm{Ph}$ & $46 \times x \mathrm{t}(12 ; 22)$ \\
\hline 10. & Complex variant $\mathrm{Ph}$ & 46 xy $\mathrm{t}(6 ; 9 ; 22)$ \\
\hline 11. & Complex variant $\mathrm{Ph}$ & $46 \mathrm{xx} t(5 ; 9 ; 22)$ \\
\hline 12. & Complex variant $\mathrm{Ph}$ & $46 \times x \mathrm{t}(7 ; 9 ; 22)$ \\
\hline
\end{tabular}

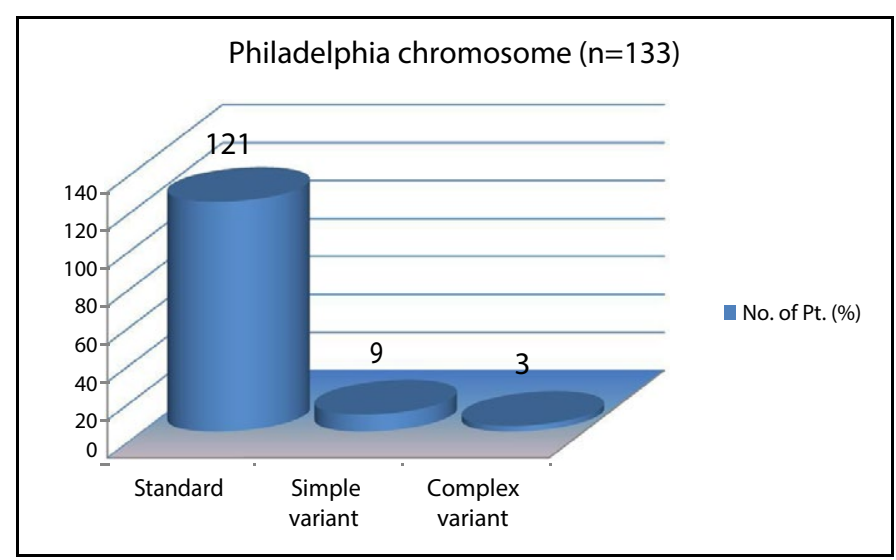

Figure 2. Frequency of Philadelphia chromosome variants.

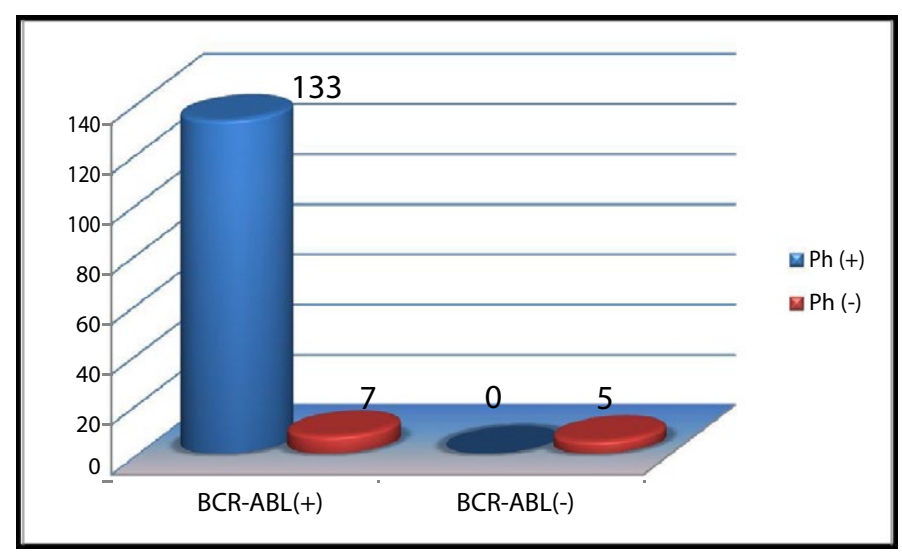

Figure 3. Frequency of bcr-abl transcripts in study population.

Table 2. Cytogenetic and molecular analysis of transcripts in cases.

\begin{tabular}{|c|c|c|c|}
\hline Transcript & Chronic Phase & Accelerated & Blast \\
\hline & $(\mathbf{n = 1 3 0})$ & Phase (n=9) & Crisis(n=6) \\
\hline $\mathrm{b} 3 \mathrm{a} 2$ & $70 \%$ & $3 \%$ & - \\
\hline $\mathrm{b} 2 \mathrm{a} 2$ & $24 \%$ & - & $1 \%$ \\
\hline $\mathrm{b} 3 \mathrm{a} 2+\mathrm{b} 2 \mathrm{a} 2$ & $34 \%$ & - & - \\
\hline $\mathrm{b} 3 \mathrm{a} 2+\mathrm{e} 19 \mathrm{a} 2$ & $2 \%$ & - & - \\
\hline $\mathrm{b} 2 \mathrm{a} 2+\mathrm{e} 19 \mathrm{a} 2$ & - & - & $2 \%$ \\
\hline
\end{tabular}

Cytogenetic and molecular analysis of transcripts of CML-chronic, accelerated and blast phases are shown in Table 2. Most frequent cytogenetic abnormalities were $\mathrm{B} 3 \mathrm{a} 2, \mathrm{~b} 2 \mathrm{a} 2$ and $\mathrm{b} 3 \mathrm{a} 2+\mathrm{b} 2 \mathrm{a} 2$ found in $70 \%, 34 \%$ and $2 \%$ of cases respectively.

\section{Disscussion}

CML is a prototype myeloproliferative disorder of bone marrow. CML is one of leukemia which may be diagnosed by typical clinical, hematological and morphological features when interpreted in a proper clinical context. Philadelphia chromosomes $(\mathrm{Ph})$ is a sine qua non of CML. Philadelphia chromosome and bcr-abl cytogenetic abnormalities must be detected in all cases of chronic, accelerated and blast crisis phases of CML [13-15].

In the present study, $\mathrm{pH}$ chromosome was detected in $90.9 \%$ of cases, the finding consistent with previous studies which had reported $\mathrm{Ph}$ chromosome in $90-95 \%$ of cases [14-16]. Additional cytogenetic 
abnormalities were detected in $70 \%$ of cases in present study as shown in Table 2 .

The findings are in full agreement with previous studies which had reported a frequency of $70-80 \%[15,16]$. Most frequent cytogenetic abnormalities were $\mathrm{b} 3 \mathrm{a} 2, \mathrm{~b} 2 \mathrm{a} 2$ and $\mathrm{b} 3 \mathrm{a} 2+\mathrm{b} 2 \mathrm{a} 2$ found in $70 \%, 34 \%$ and $2 \%$ of cases respectively (Table 2 ). The findings are in keeping with previous studies from Western countries [17-21]. However, another previous study had reported less frequency of b3a2 and b2a2 in $55 \%$ and $40 \%$ [6] of cases [22] respectively. The differences might have been introduced due to sample size, sampling techniques, study designs and nonetheless geographical differences. Paz-y-Miño et al. found frequencies of $5.4 \%$ for the b3a2 transcripts and $94.6 \%$ for the b2a2 transcripts in Ecuadorian Mestizos CML patients. Findings are in contrast to present study (Table 2). Rosas-Cabral et al. detected b3a2 $B C R-A B L$ transcripts in $28 \%$ cases, b2a 2 in $59 \%$ cases, and $13 \%$ with both b3a2/b2a2 transcripts among 97 Philadelphia-positive CML Mexican cases. The findings are inconsistent with present study (Table 2). RuizArgüelles et al. studied a group of 238 Mexican Mestizos patients with $\mathrm{Ph}$ positive CML; 54.2 per cent showed b3a2 subtype, $43.2 \%$ b2a 2 and $2.5 \% \mathrm{~b} 3 \mathrm{a} 2 / \mathrm{b} 2 \mathrm{a} 2$. The findings are consistent with present study (Table 2). De Lemos et al. from Brazil performed RT-PCR for $B C R-A B L$ in 22 CML patients. Of these patients, $15(68 \%)$ were in chronic phase, five (23\%) in accelerated phase and two (9\%) in blastic phase; $59 \%$ patients had $\mathrm{b} 3 \mathrm{a} 2$ and $41 \%$ had b2a 2 transcripts. The findings of this previous study are very close to the findings of present study. Yaghmaieet al. studied 75 adult Iranian CML patients; 83\% patients expressed one of the p210 BCR-ABL transcripts (b3a2, 63\% and b2a2, 20\%), while the remaining showed one of the transcripts of b3a3, b2a3, e1a2 or coexpression of $\mathrm{b} 3 \mathrm{a} 2$ and $\mathrm{b} 2 \mathrm{a} 2 . \mathrm{b} 3 \mathrm{a} 2$ and $\mathrm{b} 2 \mathrm{a} 2$ were co-expressed in $5 \%$ patients. Mondal et al. [23] studied 122 CML patients and details of cytogenetic analysis are not provided. Out of 122, 112 (91.8\%) patients were positive for one or more of the four junctional types tested. Findings of above studies are consistent with present study. Polampalli et al. [24] studied 202 CML patients; 138 (68\%) had the b3a2 type bcrable transcript which is consistent to $70 \%$ in present study. $64(32 \%)$ had the b2a2 type which is also in keeping with our finding of $34 \%$ as shown in Table $2 . \mathrm{Ph}$ positivity in present study is in comparison to previous studies reported from India [25-28]. Present study reports Philadelphia chromosome, its variants and cytogenetic abnormalities which are consistent with most of studies mentioned in literature. Strength of present study lies in its prospective design, inclusion and exclusion criteria. Limitations of present may be small sample size and we could not analyze all of cytogenetic abnormalities due to lack of modern laboratory facilities and funding issues.

\section{Conclusion}

The present study reports Philadelphia frequency of $90.9 \%$ and cytogenetic abnormalities similar to reported from other countries. Cytogenetic and molecular studies must be conducted for better management of CML cases in our locality. Overall, this study provides further understanding of cytogenetic and molecular abnormalities in CML cases.

\section{Statement of conflict of interest}

All authors declare that they do not have any conflict of interests to declare.

\section{Acknowledgment}

We acknowledge the clinical staff at Israuniversity and Liaquat university who painstakingly helped in this project. We are thankful to Dr. Khaskali who helped us shape this manuscript.

\section{References}

1. Chauffaille Mde L, Bandeira AC, da Silva AS (2015) Diversity of breakpoints of variant Philadelphia chromosomes in chronic myeloid leukemia in Brazilian patients. Rev Bras Hematol Hemoter 37: 17-20. [Crossref]

2. Baccarani M, Deininger MW, Rosti G, Hochhaus A, Soverini S, et al. (2013) European LeukemiaNet recommendations for the management of chronic myeloid leukemia: 2013. Blood 122: 872-884. [Crossref]

3. Ishihara T, Minamihisamatsu M (1988) The Philadelphia chromosome. Considerations based on studies of variant $\mathrm{Ph}$ translocations. Cancer Genet Cytogenet 32: 75-92. [Crossref]

4. Fisher AM, Strike P, Scott C, Moorman AV (2005) Breakpoints of variant 9;22 translocations in chronic myeloid leukemia locate preferentially in the CG-richest of the genome. Genes Chromosomes Cancer 43: 383-389. [Crossref]

5. Marzocchi G, Castagnetti F, Luatti S, Baldazzi C, Stacchini M, et al. (2011) Variant Philadelphia translocations: molecular-cytogenetic characterization and prognostic influence on frontline imatinib therapy, a GIMEMA Working Party on CML analysis. Blood 117: 6793-6800. [Crossref]

6. Sandberg AA (1980) Chromosomes and causation of human cancer and leukemia. XL The Ph1 and other translocations in CML. Cancer 46: 2221-2226. [Crossref]

7. Heim S, Mittelman F (1995) Cancer cytogenetics. ( $2^{\text {nd }}$ edn). New York: Wiley Liss.

8. Jeffs AR, Benjes SM, Smith TL, Sowerby SJ, Morris CM (1998) The BCR gene recombines preferentially with Alu elements in complex BCR-ABL translocations of chronic myeloid leukaemia. Hum Mol Genet 7: 767-776. [Crossref]

9. Chauffaille ML (2008) Cytogenetics and FISH monitoring CMLduring tyrosine kinase inhibitors treatment. Rev Bras Heamtol Hemoter 30: 13-19. [Crossref]

10. Albano F, Zagaria A, Anelli L, Coccaro N, Impera L, et al. (2013) Gene expression profiling of chronic myeloid leukemia with variant $\mathrm{t}(9 ; 22)$ reveals a different signature from cases with classic translocation. Mol Cancer 12: 36. [Crossref]

11. Sweet K, Zhang L, Pinilla-Ibarz J (2013) Biomarkers for determining the prognosis in chronic myelogenous leukemia. J Hematol Oncol 6: 54. [Crossref]

12. Quintás-Cardama A, Cortes J (2009) Molecular biology of bcr-abl1-positive chronic myeloid leukemia. Blood 113: 1619-1630. [Crossref]

13. Anand MS, Varma N, Varma S, Rana KS, Malhotra P (2012) Cytogenetic \& molecular analyses in adult chronic myelogenous leukaemia patients in north India. Indian J Med Res 135: 42-48. [Crossref]

14. Vardiman JW, Melo JV, Baccarani M, Thiele J (2008) Myeloproliferative Neoplasms. In: Swerdlow SH, Campo E, Harris NL, Jaffe ES, Pileri SA, Stein H. WHO classification of tumours of haematopoietic and lymphoid tissues. Lyon: IARC Press: 32-37.

15. Rabinowitz I, Larson RS (2004) Chronic myeloid leukemia. In: Greer JP, Foerster J, Lukens JN, Rodgers GM, Paraskevas F, et al.. Wintrobe's clinical hematology. (11 edn). Philadelphia: Lippincott Williams and Wilkins: 2235-2258.

16. Simons CM, Stratton CW, Kim AS (2011) Peripheral blood eosinophilia as a clue to the diagnosis of an occult Coccidioides infection. Hum Pathol 42: 449-453. [Crossref]

17. Paz-y-Miño C, Burgos R, Morillo SA, Santos JC, Fiallo BF, et al. (2002) BCR-ABL rearrangement frequencies in chronic myeloid leukemia and acute lymphoblastic leukemia in Ecuador, South America. Cancer Genet Cytogenet 132: 65-67. [Crossref]

18. Rosas-Cabral A, Martínez-Mancilla M, Ayala-Sánchez M, Vela-Ojeda J, BahenaReséndiz P, et al. (2003) Analysis of Bcr-abl type transcript and its relationship with platelet count in Mexican patients with chronic myeloid leukemia. Gac Med Mex 139: 553-559. [Crossref]

19. Ruiz-Argüelles GJ, Garcés-Eisele J, Reyes-Núñez V, Ruiz-Delgado GJ (2004) Frequencies of the breakpoint cluster region types of the BCR/ABL fusion gene in Mexican Mestizo patients with chronic myelogenous leukemia. Rev Invest Clin 56: 605-608. [Crossref]

20. de Lemos JA, de Oliveira CM, Scerni AC, Bentes AQ, Beltrão AC, et al. (2005) Differential molecular response of the transcripts B2A2 and B3A2 to imatinib mesylate in chronic myeloid leukemia. Genet Mol Res 4: 803-811. [Crossref]

21. Yaghmaie M, Ghaffari SH, Ghavamzadeh A, Alimoghaddam K, Jahani M, et al. (2008) Frequency of BCR-ABL fusion transcripts in Iranian patients with chronic myeloid leukemia. Arch Iran Med 11: 247-251. [Crossref] 
22. Melo JV (1996) The diversity of BCR-ABL fusion proteins and their relationship to leukemia phenotype. Blood 88: 2375-2384. [Crossref]

23. Mondal BC, Bandyopadhyay A, Majumdar S, Mukhopadhyay A, Chandra S, et al. (2006) Molecular profiling of chronic myeloid leukemia in eastern India. Am J Hemato 81: 845-849. [Crossref]

24. Polampalli S, Choughule A, Negi N, Shinde S, Baisane C, et al. (2008) Analysis and comparison of clinicohematological parameters and molecular and cytogenetic response of two Bcr/Abl fusion transcripts. Genet Mol Res 7: 1138-1149. [Crossref]

25. Jacob RT, Gayathri K, Surath A, Rao DR (2002) Cytogenetic profile of chronic myeloid leukemias. Indian J Cancer 39: 61-65. [Crossref]
26. VinSheth FJ, Sheth JJ, Patel AI, Shah AD, Verhest A (2002) Usefulness of cytogenetics in leukemias. Indian J Cancer 39: 139-142. [Crossref]

27. Chavan D, Ahmad F, Iyer P, Dalvi R, Kulkarni A, et al. (2006) Cytogenetic investigation in chronic myeloid leukemia: study from an Indian population. Asian Pac J Cancer Prev 7: 423-426. [Crossref]

28. Bakshi SR, Brahmbhatt MM, Trivedi PJ, Shukla SN, Shah PM (2006) Atypical D-FISH patterns of BCR/ABL gene rearrangements in 169 chronic myeloid leukemia patients. $J$ Assoc Genet Technol 32: 164-167. [Crossref]

Copyright: (C) 2015 Ujjan I. This is an open-access article distributed under the terms of the Creative Commons Attribution License, which permits unrestricted use, distribution, and reproduction in any medium, provided the original author and source are credited. 